Journal of Engineering and Applied Sciences 14 (5): 1430-1437, 2019

ISSN: 1816-949X

(C) Medwell Journals, 2019

\title{
A Study on a Plan for an Assembly-Type Temporary Housing Facility Usable in Times of Disaster
}

\author{
Kim Min-Seok, Ju Jae-Seong, Yeom Tae-Jun and Park Mi-Jin \\ Department of Architecture, Incheon National University, 119 Academy-ro, Yeonsu-gu, \\ Incheon, Republic of Korea
}

\begin{abstract}
Natural disasters have been on the rise due to the effects of environmental pollution. In addition, man-made disasters have also, been on the rise due to the effects of urbanization. As the types of such disasters have become increasingly varied and their associated damages have also, increased in scale, interest in ensuring appropriate responses and providing supplies to disaster victims has also, increased. In light of this, there is a need to quickly provide facilities that can ensure the safety of disaster victims who have lost their homes or are in need of evacuating. This study compared domestic and overseas cases to extract factors necessary for temporary housing facilities. The ultimate goal of this study is the development of a plan that includes assembly-type temporary housing facilities with high provisional capacities that are usable prior to the establishment of permanent housing facilities.
\end{abstract}

Key words: Disaster, assembly-type, temporary, housing facility, changeability, expandability

\section{INTRODUCTION}

Background and purpose of the study: Due to the effects of climate change, the frequency of natural disasters has increased while man-made disasters have also been on the rise due to the rising population densities associated with urbanization. As the types of disasters have become increasingly varied and their scale and damages have also, become larger the number of victims of such disasters has also been on the rise. For the purpose of safeguarding minimal rights to housing and ensuring the safety of disaster victims it is essential to provide victims who have lost their homes and been evacuated a space in which they can safely reside for a certain period of time.

Because of this, temporary housing facilities capable of accommodating various types and scales of disasters, regional conditions and environmental conditions are needed and such facilities must satisfy the required standards associated with applicability and minimum area. Despite a global increase in research and development regarding spaces and forms of temporary housing facilities, there has been a lack of related studies in South Korea and due to the limited applicability of the findings of overseas research to South Korea, a plan that is appropriate for South Korea is needed. This study aims to develop a plan for temporary housing facilities that can be used until permanent housing can be provided to disaster victims who have lost their homes.
Scope and method of research: After calculating the minimum required area of temporary housing facilities, this study established the direction in which the plan for temporary housing facilities should develop in consideration of provisional capacity, safety, sustainability, changeability, potential for storage and environmental friendliness and based on analyses of domestic and overseas temporary housing facilities. As a result of these efforts, forms of temporary housing facilities and cluster layouts were proposed and further studies regarding their suitability were undertaken. Before engaging in research, the previous research was analyzed to identify problems and analyze the means of improving and developing existing temporary housing facilities. Using factors extracted from the analysis of cases, methods of improvement were proposed. The temporary housing facilities discussed in this study are limited to the residential sector, core sector facilities are excluded from this study.

Analysis of existing research: Kyeong-Nam et al. (2007) undertook research to develop temporary housing facilities that address the disadvantages of some temporary housing facilities. These research efforts, however do not include considerations for provisional capacity and are focused on improving residential environments regarding the supply of space that provide physical safety for disaster victims who have lost their homes.

Corresponding Author: Kim Min-Seok, Design Environment Laboratory \#524, 28 Dong, 119 Academy-ro, Yeonsu-gu, Incheon, Republic of Korea 
Yeong-Hak et al. (2011) undertook comparative research related to minimum residential spaces in South Korea and Japan based on Post Occupancy Evaluations (POE) associated with assembly-type housing deployed during the shelling of Yeonpyeong Island. The study proposed plans based on different combinations of modular units that account for differences in the size and composition of the families of disaster victims. However, like the first study mentioned, this study, also, focused on improving the residential environment of disaster victims and excluded further studies associated with provisional capacities.

The study that most closely resembles the current one was the study by Dong-Un and Tae-Hyeon (2011) on panel assembly-type temporary housing facilities capable of quick deployment due to the use of panel modules and lightweight materials. However, the solution proposed by this study had shortcomings in the area of simplicity and panel production in that a total of 9 modules were needed for assembly.

Using the findings of 3 domestic and overseas research papers, data from $6 \mathrm{WHO}$, UN and IFRC reports and cases of uses of outdoor temporary housing facilities between 2001 and 2013 in Southeast Asia, Sara and Kyeong-Sook (2015) published a study regarding the 'features and details required of temporary housing during times of disaster' and this was considered as appropriate to use as reference material for this study.

Review and analysis of domestic and overseas temporary housing facilities: Comparative analyses and case studies regarding domestic and overseas temporary housing facilities were undertaken. By referring to the features of existing research, criteria appropriate for South Korea were extracted. The criteria consist of 6 technological aspects and 2 environmental aspects. The comparative analysis table is as presented in Table 1.

A total of 8 cases of temporary housing facilities including 2 domestic and 6 overseas cases were studied. The study contents are as shown in Table 2 .

Container type-(A) is a facility initially used as a temporary housing facility in South Korea that is a simple improved version of a container. Such facilities did not consider any aspects associated with assembly and changeability and were inconvenient to transport and store. This type of facility had no structural problems but lacked facilities fit for residential environments and did not account for any layout planning. To address this issue, assembly type housing-(B) was manufactured. However, this type of facility proved difficult to assemble on-site and was developed without consideration of the need for facility expansions. In the case of overseas
Table 1: Comparative analy sis table

Characteristics/Criterion Details

Technological

Transport ability

A criterion used to compare different loads appropriate for transportation for the purpose of deployment

Storage ability

A criterion used to compare the ability to preserve the durability of a facility during storage for the purpose

of preventing one-time use

Structurality A criterion used to compare structural autonomy in response to outdoor environments

Assemblability A criterion used to compare the number of tools needed for assembly or the simplicity of assembly during installation of facilities

Changeability A criterion used to compare additional expandability, time needed to install or the simplicity of the installation and transportation process

Environmental A criterion used to compare the composition friendliness

Environmental

Sustainability of environmental friendly materials in a facility

Layout plan

A criterion used to compare minimal amounts of energy generation

A criterion used to compare layout plans and the existence of layout plaming accounting for greater psychological stability of disaster victims

Table 2: Comparative analysis table of south korean temporary housing facilities characteristics

\begin{tabular}{lcccccccc}
\hline Criterion & A & B & C & D & E & F & G & H \\
\hline Technological & & & & & & & & \\
Transportability & $\Delta$ & $\circ$ & $\circ$ & $\circ$ & $\circ$ & $\circ$ & $\circ$ & $\Delta$ \\
Storage ability & $\Delta$ & $\Delta$ & $\Delta$ & $\Delta$ & $\circ$ & $\circ$ & $\circ$ & $\Delta$ \\
Structurality & $\circ$ & $\Delta$ & $\Delta$ & $\Delta$ & $\Delta$ & $\Delta$ & $\Delta$ & $\circ$ \\
Assemblability & $\times$ & $\Delta$ & $\circ$ & $\Delta$ & $\times$ & $\circ$ & $\Delta$ & $\times$ \\
Changeability & $\times$ & $\times$ & $\times$ & $\Delta$ & $\circ$ & $\Delta$ & $\Delta$ & $\circ$ \\
Environmental & $\times$ & $\times$ & $\Delta$ & $\times$ & $\Delta$ & $\Delta$ & $\circ$ & $\circ$ \\
Friendliness & & & & & & & & \\
Environmental & & & & & & & & \\
Sustainability & $\Delta$ & $\circ$ & $\Delta$ & $\Delta$ & $\times$ & $\Delta$ & $\Delta$ & $\circ$ \\
Layout plan & $\times$ & $\Delta$ & $\times$ & 0 & $\times$ & $\circ$ & $\times$ & $\times$ \\
\hline
\end{tabular}

o: Excellent application of the criterion; $\Delta$ : Partial application of the criterion; $\times$ : No application of the criterion

facilities with the exception of EDV-01 (Emergency Disaster Vehicle-01)-(H) most of the facilities took transportability into consideration. The facilities, also, needed only small spaces for storage but there were concerns over reduced durability. However, in the case of MyHab- $(\mathrm{C})$ its envelope which is based on recyclable plastics, makes it possible for it to be easily replaced in the event of damage. In addition, most of the facilities were designed to have a changeable structure or assembly-type structure for the purpose of convenient transportation and Recovery Huts-(F) were found to have excellent cluster layout plans. Upon opening the EDV-01 (Emergency Disaster Vehicle-01)-(H) the facility expands to include 2 floors. The facility presented the most excellent residential environment with residential spaces in the 2nd floor and spaces for other facilities in the 1st floor, yet was lacking in terms of provisional capacity (Table 3) (Hannah and Kil-Yong, 2004; Hyun-Sun, 2016; Won et al., 2015; Woo-Chul et al., 2012, 2013). 
Table 3: Cases of temporary housing facilities

\begin{tabular}{|c|c|c|c|}
\hline Items & Photo & Features & Parameters \\
\hline \multirow[t]{3}{*}{ Container type (A) } & & Size & $20 \mathrm{ft}, 6,000 \times 2,450 \times 2,650 \mathrm{~m}^{3}$ \\
\hline & & Spatial composition & $\begin{array}{l}\text { No separate composition of spaces; Flooring has been } \\
\text { renovated for winter season insulation and heating purposes }\end{array}$ \\
\hline & & Materials & Same materials as existing containers \\
\hline
\end{tabular}

Assembly

type housing (B)

Myhab (C)

Sphere emergency

shelter (D)

Recovery

shelter $(\mathrm{E})$

Recovery huts (F)

Better shelter of

IKEA foundation $(\mathrm{G})$

EDV-01 (Emergency $6058 \times$ Disaster vehicle- 01$)(\mathrm{H})$
Size

Spatial composition

Materials

Spatial composition

Materials; Frame

Walls

Environmental friendliness

Spatial composition

Materials; Frame

Interior

Exterior

Environmental friendliness

Expandability

Spatial composition

Materials

Environmental friendliness

Convenience

Changeability

Size

Spatial composition

Materials; Frame

Walls

Provisional capacity

Convenience

Module size

Spatial composition

Materials; Frame; Panel

Environmental friendliness

Convenience

Module size

Module area

Spatial composition

2 Floors

1 Floors

1 Kitchen

1 Shower room

1 Capacitor room

Materials
$6,000 \times 3,000 \mathrm{~mm}^{2}$

Living Room 1, Kitchen 1, Bathroom 1, Storage room 1, Boiler room 1

Sandwich panels including fire resistant materials

Single space, 2 person housing

Recyclable plastic

Waterproof boards

Use of recyclable plastic

Composed of 19 lower area tents and roofing

Fibreglass plastic

Lightweight nylon material

Waterproof canvas

Long lifespan, recyclable

Expansion and contraction of spaces using partitions

Single space with no partitions

Non-toxic polypropylene

Collection of water achieved through roofing structure; $100 \%$ recyclable

Blocking of outdoor air reinforced using on-site materials

1 man installation under 1 minute possible

Transportation in a horse-shoe shape or board shape possible

Shapes change according to unfolding methods

Width $3 \sim 3.6 \mathrm{~m}$, Height $2.4 \mathrm{~m}$ (7.89)

Single space; Bent shaped area $0.6 \mathrm{~m}$ in height on top of the $1.8 \mathrm{~m}$ structure used as storage space

Biax material

Biax material, semi-transparent material allowing natural light

1 man assembly under $30 \mathrm{~min}$. possible. Composed of 4 overlapping pieces in which each piece does not weigh more than $27.21 \mathrm{~kg}$

Possible to connect all shelters

$3320 \times 5680 \times 2830 \mathrm{~mm}^{2}\left(17.5 \mathrm{~m}^{2}\right)$

Single residential space

Galvanized steel, Polyolefin with UV blocking features

PV system solar panels; Roof ventilation

Possible to individually replace parts; Recyclable

Two board-type package boxes weighing $80 \mathrm{~kg} 4$ man

assembly within 4-8 hours without tools possible

1 Floor: $6058 \times 2591 \times 2438 \mathrm{~mm}^{2}$ (WHD) 2 Floors: $4511 \times 2438 \mathrm{~mm}^{2}$ (WHD)

$15.7 \mathrm{~m}^{2}$

1 Bedroom; 2 foldable beds, 2 seats, 4 shelves

1 Bathroom; 1 Bathroom

1 Sink and stove

1 Shower room

1 Li-ion capacitor, 1 Fuel cell

Aluminum 

remover (collects water vapors); Decomposition of fecal matter using microorganisms; Hydrogen generation

Convenience Container modules that are convenient to transport; Automatic leveling adjustment device; Electrical instantaneous water heating; Power storage and collection of water

Changeability Envelope elevates to form 2 nd floor

Such facilities were easy to supply and install. Yet, due to their typical application in warm climates, their applicability in countries having four distinct seasons such as South Korea is limited. This highlights a need for further improvements regarding the selection of materials and structural performances. The comparative analysis table of the 8 facilities is presented in Table 3 .

\section{MATERIALS AND METHODS}

Proposed direction of temporary housing facility developments: An analysis of the case studies above indicated, first, the existence of a key problem associated with domestic container type facilities involving its lack of consideration for storage and transportation. To resolve this issue, assembly type and modular type facilities were applied in the cases, in consideration of the future need for facility expansions and layout planning, the assembly type was deemed appropriate. Second, considerations for structural stability associated with problems typically found in temporary housing facilities suitable for warm climates were lacking. Facilities appropriate for South Korea, a country having four distinct seasons, must have durable envelopes and structural frames capable of withstanding the weight of the facility. Third, the nature of temporary housing facilities means that energy supply is difficult. In facilities used overseas, additional facilities such as solar photovoltaic panels and water collectors were installed to solve this problem. Fourth, facility expansion and layout plans must consider differences in the composition of disaster victim families and the scale of disasters. Fifth, the temporary housing facilities must allow for repairs and storage for reuse after recovery from a disaster. A means of reducing the volumes of the facilities must be considered and the facilities must be manufactured to enable easy partial repairs should they be needed.

Calculation of floor areas of temporary housing facilities: A floor area of $3,000 \times 2,400 \mathrm{~mm}$ which is the size of a $10 \mathrm{ft}$ container was calculated as an area appropriate for rapid deployment. This is a size that allows for loading on a 2.5 ton truck. Considering that as per the (Disaster Relief Planning Guidelines) an area of $3.3 \mathrm{~m}^{2}$ per person is

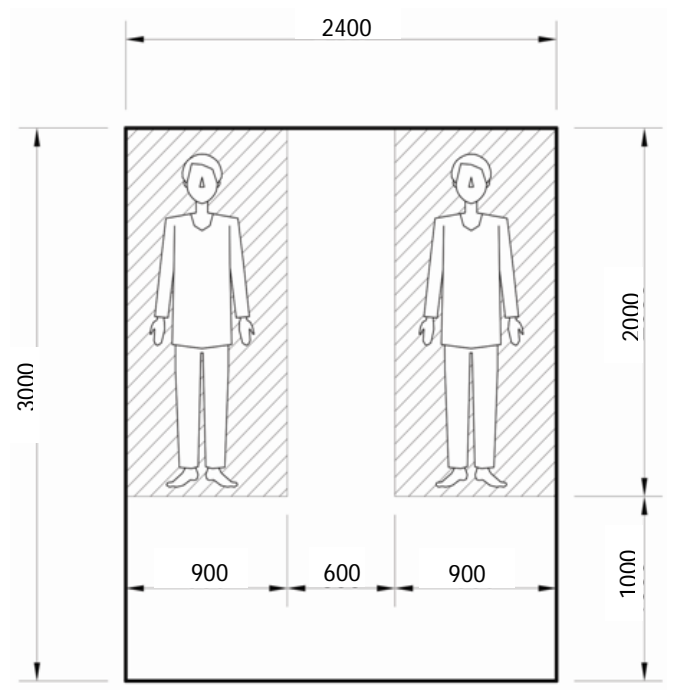

Fig. 1: Calculation of floor area

to be provided, an area of $3.000 \times 2.400 \mathrm{~mm}\left(7.200 \mathrm{~mm}^{2}\right) \mathrm{can}$ be used by two people. In consideration of the narrow spaces, sleeping areas were planned to be $2.000 \times 900 \mathrm{~mm}$ which is smaller than a single sized bed (Fig. 1).

A proposal for an outdoor temporary housing facility: The proposed method involved the assembly of wall panels categorized as A and B-type panels. The thickness of the panels was the same at $50 \mathrm{~mm}$. The A-type panel was $2,400 \times 2,400 \mathrm{~mm}$ and included an entrance with a width and length of $900 \times 1,800 \mathrm{~mm}$. The B-type panel was $3,000 \times 2,400 \mathrm{~mm}$ and included a window with a width and length of $1,200 \times 600 \mathrm{~mm}$. Materials capable of withstanding loads, external impacts and environmental considerations while being lightweight were planned for use.

A frame was provided to fix the corner areas of the panels during assembly. The 3 frames were designed to be foldable for storage by having the frames connected through hinges between the frames. During assembly, the frames and panels come together which is expected to make the hinges structurally irrelevant. The frames were based on $50 \times 50 \mathrm{~mm}$ sized rods and the wall panels and frames were each distinguished as male and female parts joined together. 
The ceiling panel was planned to be $200 \mathrm{~mm}$ thick. In consideration of load factors, only solar photovoltaic panels for electrical supply were installed. This resulted in the supply of power being somewhat lacking and only lightweight flexible solar photovoltaic panels were used.

The floor panel was planned to be at a height of $300 \mathrm{~mm}$ to block cold temperatures from the ground's surface. A foldable table and mattress were included indoors. Due to the application of a hard mattress cover, the cover can be closed during normal times. As the foldable table can potentially be stored underneath the floor, the area can be used as a flat floor as is the case for general living room areas. A unit section was planned to be included between the two mattresses in which capacitors storing electricity generated from the ceiling solar photovoltaic panels or other facilities can be installed.

The total thickness of overlapping the $300 \mathrm{~mm}$ floor panel, $200 \mathrm{~mm}$ ceiling panel and four $50 \mathrm{~mm}$ walls is 700 $\mathrm{mm}$ having a width and length of $3,000 \times 2,400 \mathrm{~mm}$. These dimensions make it possible to store 8 facilities in an area equal to that occupied by a $20 \mathrm{ft} 6,000 \times 2,400 \times 2,500 \mathrm{~mm}$ sized container (Fig. 2-4).

Cluster layout plan: Assembly-type temporary housing facilities include methods of simple layout types and mixed clustering types. Simple layout types of joining regard a layout involving the separate joining of residential sectors and core type modules which has the advantage of having a hallway and a place where people can gather. However, this is not different from existing facilities and does not entail joining with a core sector, resulting in structural instability.

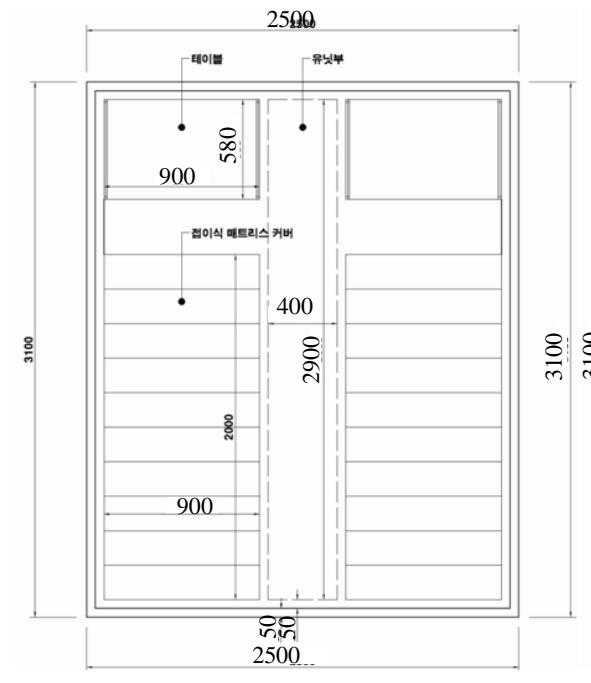

Mixed types of joining involve a method of joining the residential sector with the core type module. The method involves joining with the core type module by removing the wall of the area to be joined. Joining types have a disadvantage in that hallways and living room areas cannot be freely created. However, due to the separate joining of the core type module and the temporary housing facility the resulting structure is structurally safer (Fig. 5 and 6).

Analysis of the temporary housing facility plan: Assembly-type outdoor temporary housing facilities have the same dimensions as $10 \mathrm{ft}$ sized containers and are more easily loadable and transportable compared to

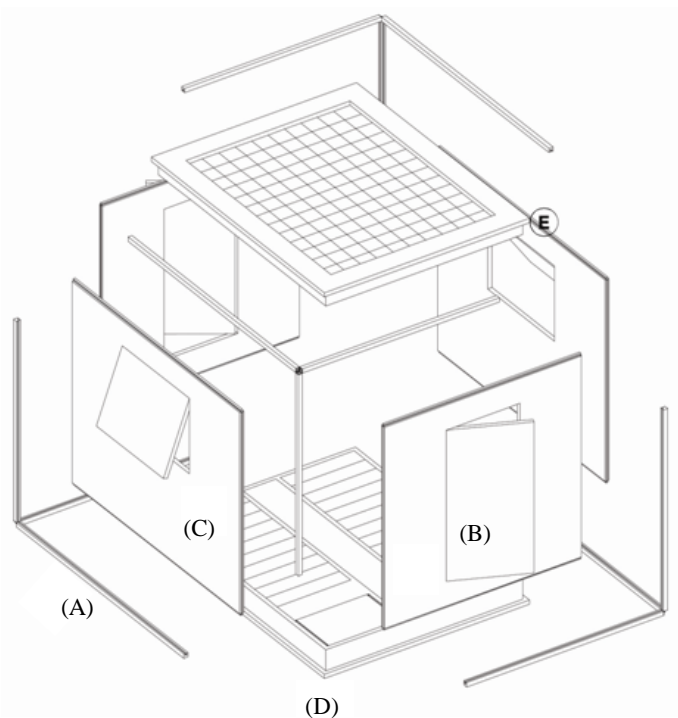

Fig. 2: Disassembly map

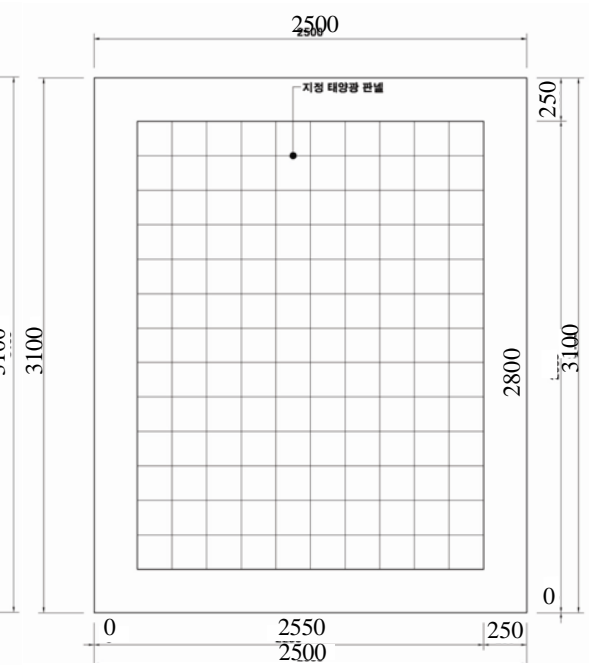

Fig. 3: Floor plan 
(a)

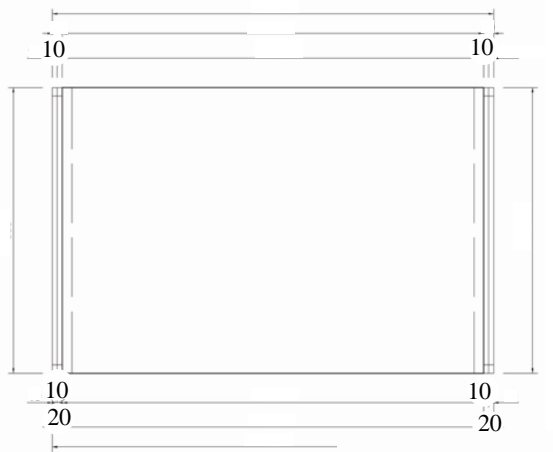

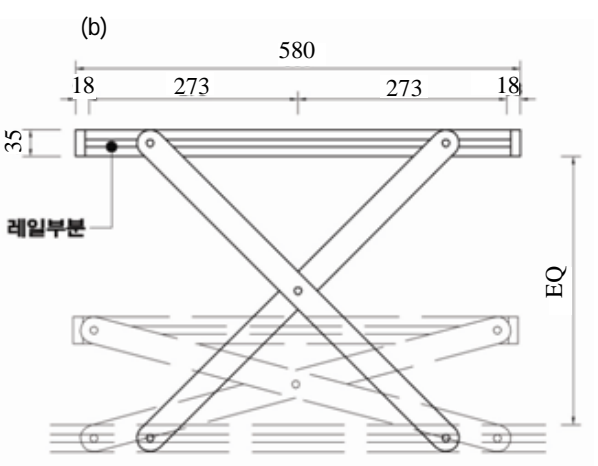

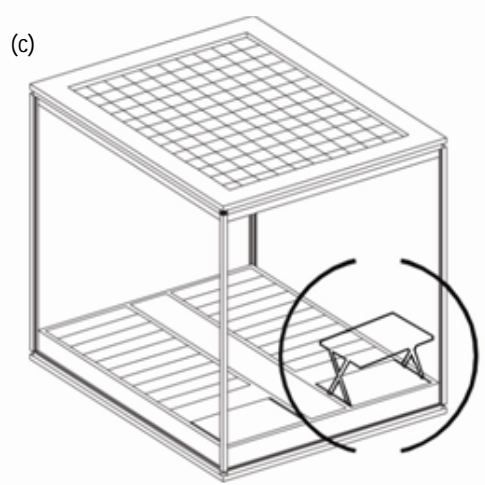

Fig. 4: a-c) Foldable table detailed drawings

(a)

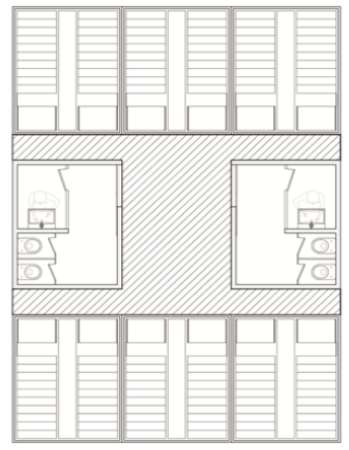

(b)

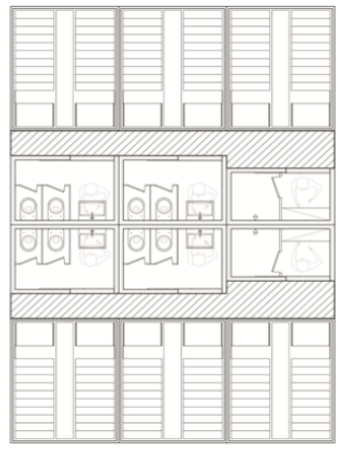

Fig. 5: a, b) Simple layout type (a)

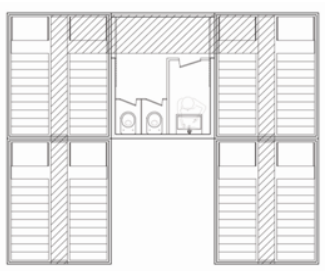

(c)

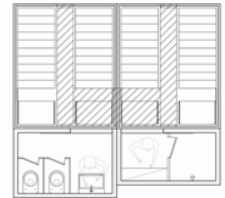

(b)

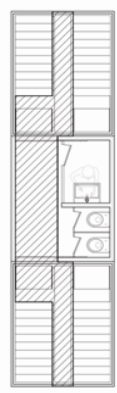

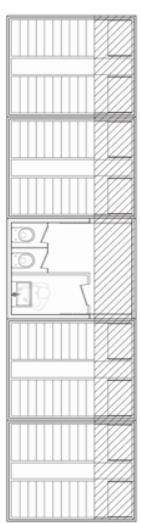

Fig. 6: a-c) Joining type
Table 4: Comparative analysis table of south korean temporary housing facilities

\begin{tabular}{lc}
\hline Characteristics/Criterion & $\begin{array}{c}\text { Assembly-type outdoor } \\
\text { temporary housing facility }\end{array}$ \\
\hline Technological & \\
Transportability & 0 \\
Storage ability & 0 \\
Structurality & 0 \\
Assemblability & 0 \\
Changeability & $\times$ \\
Environmental & $\Delta$ \\
Friendliness & \\
Environmental & \\
Sustainability & \\
Layout plan & $\Delta$ \\
\hline
\end{tabular}

existing temporary housing facilities. The facility is also lightweight and is made from highly durable materials which lessen concerns that its durability could be compromised during storage. Due to the frames and wall panels interlocking together, the facility is structurally stable and is easy to install thanks to its slide method of assembly. Its walls are also, removable due to it being an assembly-type facility which makes it excellent for layout planning, via., means of joining facilities. Also as it is an assembly-type facility, changeability was not considered. The facility had the disadvantage of only having solar photovoltaic panels for use as self-energy producing facilities for its residential sector module excluding the core module. Because of this its use solely as an assembly-type temporary housing facility was considered to result in reduced levels of sustainability (Table 4). 


\section{RESULTS AND DISCUSSION}

There are three discussion topics in this study: First, the development of a core type temporary housing facility. The temporary housing facility proposed in this study corresponds to the residence of the victims. For this reason, facility such as toilets, showers and kitchens are required for living. Therefore, it is essential to develop core type temporary housing facilities. However, in the case of core type temporary housing facilities, a lot of facilities such as water supply system, electrical system, ventilation system are facility system. Installing the facility system in a temporary housing facility will increase the cost of production. In addition, special care is required for transportation, loading and storage and repair costs are expected to increase in the event of damage to the facility system. There is also, a disadvantage that it is not easy to use because the facility system has been added in large quantities. We need to discuss how to address these issues and requirements.

Secondly, it is about the post-occupancy evaluation through the actual production. Since, it is still in the planning stage in development it is doubtful about the performance of the facilities after production. It is made lightweight for storage and transportation and in order to cope with the external environment, the exterior of the facility was also, considered. Also, partial repair due to breakage was considered but discussion is needed to see if you will be able to achieve the desired performance when using temporary housing in an extreme environment.

Third, it discusses economic aspects of temporary housing facilities. Because it is a planning stage in development it is somewhat difficult to grasp the economic part. It was made to be able to repair parts in case of breakage and it is modular, so, it is expected to be economical. However, it is difficult to know how much it will cost in actual production. Since, the economical aspects of using temporary housing facilities can not be overlooked it is necessary to discuss how to reduce the cost of production (Jung-In and Sang-Ho, 2006; Kang and Hakkyong, 2016; Lee and Yoe, 2016; Park and Kim, 2017).

\section{CONCLUSION}

Disaster victims require residential spaces where they can reside for a certain period. This study undertook research into the design of temporary housing facilities that can be effectively and quickly supplied in the event of a disaster.
Typical temporary housing facilities in South Korea were found to lack considerations for transport and loading issues and also, were found to lack facilities to supply energy. In addition, the adding of more facilities was the only solution in the event of a lack of space. The absence of cluster layout plans meant that a community capable of providing psychological stability to disaster victims was not possible (Yun, 2016).

In overseas cases, several examples of facilities that considered provisional capacities over residential environments were found to exist and were considered appropriate for use until permanent housing could be provided. In consideration of the simplification and load bearing capacities of the facilities, there were rarely any instances of facilities installed with high capacity energy generation equipment. However, several of the facilities were installed with minimal energy generation equipment. Such facilities, also, took expandability and spatial conservation into consideration by employing assembly-type and open-type models.

Based on the case analyses, a temporary housing facility plan was proposed. First, the plan involved the use of an assembly-type facility that was easily loadable and transportable for quick supply. Second, a facility having an envelope capable of withstanding outdoor environments during all 4 seasons and made from highly durable materials was considered necessary. Third, solar photovoltaic panels were installed for the purpose of supplying minimal amounts of energy. Fourth, the plan involved a means of connecting the facilities together for further application in layout planning. Fifth, the facility considered the need for further dismantling and storage after the disaster situation ended. A facility capable of maintaining durability through non-application of loads during dismantling and a facility capable of conveniently being repaired in separate parts was considered (Yeun-Sook et al., 2013).

The temporary housing facility proposed in this study can be used to ensure the safety of disaster victims through its rapid supply and is expected to provide appropriate periods of relief before permanent housing facilities can be installed. In addition, through cluster layouts, the facilities had the advantage of being able to form communities in which disaster victims can establish a sense of psychological stability.

\section{RECOMMENDATIONS}

As this study focused only on the planning of the residential sector, future research regarding core type modules is needed. Solar photovoltaic panels were installed in the residential sector for the purpose of 
conserving space and establishing structural stability. Additional research regarding the facilities needed to improve the residential environments of disaster victims in the core type modules is also, needed. Further advancement of the layout plan should be achieved through further study of the joining area of the core-type module. As this is a study regarding plans, $\mathrm{POE}$ regarding the facility was not possible. POE through mock-ups is considered to be needed and further supplementary research to account for problems discovered during this process is also, required.

\section{ACKNOWLEDGEMENT}

This research was supported by a grant (17CTAP-C115046-02) from Technology Advancement Research Program (TARP) funded by Ministry of Land, Infrastructure and Transport of Korean government.

\section{REFERENCES}

Dong-Un L. and P. Tae-Hyum, 2011. A basic research for development of emergency housing model in Islands. J. Korean Hous. Assoc., 22: 35-45.

Hannah, L. and P. Kil-Yong, 2004. A study on the methods of temporary housing for the refugee disastered. J. Archit. Inst. Korea Acad. Conf. Plann. Des., 24: 143-146.

Hyun-Sun, K., 2016. [A study on considerations and methods to establish an effective disaster recovery system (In Korean)]. Secur. Eng. Res., 13: 487-500.

Jung-In, M. and L. Sang-Ho, 2006. Lin construction and overseas large scale construction application: London Heathrow airport. J. Archit. Inst. Korea, 22: 141-148.

Kang, W. and K. Hakkyong, 2016. [A comparative study into the USA's disaster management system: Focused on all-hazard approach and CERT program (In Korean)]. J. Secur. Eng., 13: 41-54.
Kyeong-Nam, L., M. Jung-In, K. Hong-Yong, L. KangHee and Y. Sang-Ho, 2007. A Study on Manufacture of Mock-up in Terms of Improved Temporary Residences. Architectural Institute of Korea, Korea, East Asia,

Lee, M.H. and H. Yoe, 2016. [Design of ICT based protected horticulture for recovering natural disaster (In Korean)]. Asia Pac. J. Multimedia Serv. Convergent Art Humanities Sociology, 6: 373-382.

Park, J.K. and M.G. Kim, 2017. PPK GNSS system based UAV photogrammetry for construction of urban disaster prevention information. Asia Pac. J. Multimedia Serv. Convergent Art Humanities Sociology, 7: 355-362.

Sara, K. and N. Kyung-Sook, 2015. A study on spatial characteristics of post-disaster interim housing focusing on Asian precedents of natural disasters. Korean Inst. Interior Des. J., 24: 108-116.

Won, M.S., K.K. Hee and N. Ken, 2015. [A study on necessary elements for refugees' stability in temporary housing (In Korean)]. Digital Des. Stud., 15: 501-510.

Woo-Chul, W., L. Chang-Jae and L. Suk-Ho, 2013. A study on the planning characteristic of temporary housing considering the needs of temporary residence. J. Archit. Inst. Korea Plann. Des., 33: 39-40.

Woo-Chul, W., S. Young-Hak and L. Suk-Ho, 2012. A research study on comparative analysis of architectural planning improvement on temporary housing of Korea and Japan. J. Archit. Inst. Korea Plann. Des., 28: 29-37.

Yeun-Sook, L., C. Jae-Woo and L. Ji-Hye, 2013. Case study on temporary houses for poor class residents. Asia Digital Art Des Assoc., 1: 444-445.

Young-Hak, S., L. Seok-Ho and W. Woo-Chul, 2011. A study of temporary housing design with unit modular method. J. Archit. Instit. Korea, 29: 155-162.

Yun, H.J., 2016. [A model for urban regeneration by constructing contemporary publicness (In Korean)]. Asia Pac. J. Multimedia Serv. Convergent Art Humanities Sociology, 6: 657-666. 